Original investigation

Open Access

\title{
Comparison of rosuvastatin and atorvastatin for lipid lowering in patients with type 2 diabetes mellitus: results from the URANUS study
}

\author{
Christian Berne*1, Annica Siewert-Delle ${ }^{2}$ and the URANUS study \\ investigators
}

Address: ${ }^{1}$ University Hospital, Uppsala, Sweden and ${ }^{2}$ AstraZeneca Sverige AB, Sweden

Email: Christian Berne* - christian.berne@akademiska.se; Annica Siewert-Delle - Annica.Siewert-Delle@astrazeneca.com

* Corresponding author

Published: 03 June 2005

Cardiovascular Diabetology 2005, 4:7 doi:10.1 186/1475-2840-4-7

This article is available from: http://www.cardiab.com/content/4/I/7

(c) 2005 Berne et al; licensee BioMed Central Ltd.

This is an Open Access article distributed under the terms of the Creative Commons Attribution License (http://creativecommons.org/licenses/by/2.0), which permits unrestricted use, distribution, and reproduction in any medium, provided the original work is properly cited.
Received: 15 April 2005

Accepted: 03 June 2005

\begin{abstract}
Objective: The Use of Rosuvastatin versus Atorvastatin iN type 2 diabetes mellitUS (URANUS) study compared rosuvastatin with atorvastatin for the reduction of low-density lipoprotein cholesterol (LDL-C) in patients with type 2 diabetes.

Methods: After a 6-week dietary run-in, patients aged $\geq 18$ years with type 2 diabetes and LDL$C \geq 3.3 \mathrm{mmol} / \mathrm{L}$ were randomised to double-blind treatment with rosuvastatin $10 \mathrm{mg}(\mathrm{n}=232)$ or atorvastatin $10 \mathrm{mg}(\mathrm{n}=233)$ for 4 weeks. Doses were then titrated up to a maximum of rosuvastatin $40 \mathrm{mg}$ or atorvastatin $80 \mathrm{mg}$ over 12 weeks to achieve the 1998 European LDL-C goal (<3.0 mmol/L).

Results: Rosuvastatin reduced LDL-C levels significantly more than atorvastatin during the fixeddose and titration periods $(p<0.000 \mathrm{I})$. Significantly more patients reached the $1998 \mathrm{LDL}-\mathrm{C}$ goal with rosuvastatin $10 \mathrm{mg}$ compared with atorvastatin $10 \mathrm{mg}$ at 4 weeks $(81 \%$ vs $65 \%, \mathrm{p}<0.00 \mathrm{I})$. At 16 weeks, significantly more patients achieved their LDL-C goal with rosuvastatin compared with atorvastatin $(94 \%$ vs $88 \%, \mathrm{p}<0.05)$ and more patients receiving rosuvastatin remained at their starting dose with reduced requirement for dose titration. At 4 weeks, $65 \%$ of rosuvastatin patients had reached their 2003 European LDL-C goal $(<2.5 \mathrm{mmol} / \mathrm{L})$, compared with $33 \%$ of atorvastatin patients $(p<0.000 I)$. Both treatments were similarly well tolerated with no unexpected safety concerns.
\end{abstract}

Conclusion: At the start dose and following dose titration, rosuvastatin was significantly more effective than atorvastatin at reducing LDL-C and achieving European LDL-C goals in patients with type 2 diabetes.

\section{Introduction}

The prevalence of type 2 diabetes in adults was estimated at $2.8 \%$ worldwide in 2000 , and predicted to increase to $4.4 \%$ by 2030 [1]. Patients with type 2 diabetes have a risk of cardiovascular disease approximately two- to fourtimes greater than that in the non-diabetic population [2]. Furthermore, their prognosis is worse; in a Swedish study the 5-year mortality rate after myocardial infarction was 
$55 \%$ for patients with diabetes compared with 30\% in patients without diabetes $(\mathrm{p}<0.001)$, and the re-infarction rates were $42 \%$ and $25 \%$, respectively ( $p<0.001$ ) [3]. More recent data reflecting the outcome of new evidencebased interventions in acute myocardial infarction demonstrate that the difference between diabetic and non-diabetic subjects is still present, showing a 1-year mortality in males of $22.3 \%$ versus $13.0 \%$ in males and $26.1 \%$ versus $14.4 \%$ in females [4]. In the US National Health and Nutrition Examination Survey (NHANES I), the ageadjusted mortality rate in diabetic patients over 9 years of follow-up was double that in non-diabetic patients, and cardiovascular disease accounted for $75 \%$ of the excess mortality in men and 57\% in women [5].

The elevated cardiovascular risk in patients with type 2 diabetes is primarily attributed to the clustering of atherogenic risk factors, including dyslipidaemia, hypertension, abdominal obesity, left ventricular hypertrophy, and impaired fibrinolysis [6]. For patients with diabetes, European Diabetes Policy Group guidelines published in 1999 and European guidelines for coronary heart disease prevention published in 1998, both recommend that lowdensity lipoprotein cholesterol (LDL-C) levels should be $<3.0 \mathrm{mmol} / \mathrm{L}[7,8]$. More recent (2003) European guidelines on cardiovascular disease prevention also recognise type 2 diabetes as a risk factor, and recommend more stringent LDL-C reductions to $<2.5 \mathrm{mmol} / \mathrm{L}$ [9]. In addition, this goal is recommended by both the American Diabetes Association and the US National Cholesterol Education Program Adult Treatment Panel III [10,11].

Statins are recognized as first-line therapy for cholesterol lowering $[7,11]$, and have been proven to reduce cardiovascular morbidity and mortality in large outcome trials in various populations [12-17]. The benefits of statin therapy extend to patients with diabetes, as shown by subgroup analyses of patients with diabetes in several of the major statin outcome studies, including the Cholesterol And Recurrent Events (CARE) study, the Scandinavian Simvastatin Survival Study (4S), the Long-Term Intervention with Pravastatin in Ischemic Disease (LIPID) study and the Heart Protection Study [18-21]. The Collaborative Atorvastatin Diabetes Study (CARDS) recently investigated the effects of lipid lowering with statin therapy specifically in patients with type 2 diabetes [22]. The primary endpoint, time to the first occurrence of acute coronary events, coronary revascularisation or stroke, was significantly reduced by $37 \%$ in patients treated with atorvastatin $10 \mathrm{mg}$ compared with placebo $(\mathrm{p}=0.001)$. In addition, LDL-C levels were significantly reduced by $40 \%$ in the atorvastatin $10 \mathrm{mg}$ group compared with the placebo group $(\mathrm{p}<0.001)$ [22].
Despite the proven benefits of statin therapy, studies suggest that many patients with diabetes fail to achieve lipid goals in clinical practice $[23,24]$. Statins differ in their lipid-modifying efficacy and their ability to enable patients to achieve lipid goals [25,26]. Trials in patients with hypercholesterolaemia have shown that rosuvastatin is more effective than atorvastatin at reducing LDL-C and achieving US and/or European LDL-C goals over treatment periods ranging from 6 to 52 weeks [25-30]. The URANUS (Use of Rosuvastatin versus Atorvastatin iN type 2 diabetes mellitUS) study is a direct comparison of the effects of rosuvastatin with atorvastatin on LDL-C, other plasma lipids and LDL-C goal achievement in patients with diabetes. This study was designed to reflect the optimal treatment of diabetic dyslipidaemia in the clinical setting, in that statin dose was titrated upwards from the recommended start dose to that required to enable patients to achieve LDL-C goal.

\section{Methods \\ Patients}

Patients (male or female) aged 18 years or more were eligible for the study if they had a history of type 2 diabetes for at least 3 months; were being treated with diet, oral antidiabetic medication, insulin or a combination of these treatments; and had fasting LDL-C of $\geq 3.3 \mathrm{mmol} / \mathrm{L}$ and triglycerides (TG) of $<6.0 \mathrm{mmol} / \mathrm{L}$ at enrolment. Exclusion criteria included: type 1 diabetes; uncontrolled type 2 diabetes; uncontrolled hypothyroidism or hypertension; nephrotic syndrome or severe renal failure; active liver disease or hepatic dysfunction; active arterial disease (e.g., unstable angina, myocardial infarction, transient ischaemic attack, cerebrovascular accident, coronary artery bypass grafting or percutaneous transluminal coronary angioplasty within 3 months before beginning the study); serum creatinine kinase (CK) levels $>3 \times$ the upper limit of normal (ULN); body mass index $>35 \mathrm{~kg} / \mathrm{m}^{2}$; and known hypersensitivity to statins. All patients gave written informed consent, and the study was conducted in accordance with the Declaration of Helsinki.

\section{Study design}

The trial was a randomised, double-blind, parallel-group study (4522SE/0001) conducted in 51 centres in Sweden. The study design is summarised in figure 1. Patients meeting the inclusion and exclusion criteria at enrolment entered a 6-week dietary run-in period and all lipid-lowering therapy was withdrawn at least 14 days before the end of this period. Patients with fasting LDL-C $\geq 3.3$ $\mathrm{mmol} / \mathrm{L}$ were then randomised to a starting dose of either rosuvastatin $10 \mathrm{mg}$ or atorvastatin $10 \mathrm{mg}$ for 4 weeks. This was followed by a 12-week period of dose titration, making a total of 16 weeks of treatment. Patients who had not reached the 1998 European guideline goal of LDL-C $<3.0$ $\mathrm{mmol} / \mathrm{L}$ [7] after 4 weeks were titrated up by doubling the 


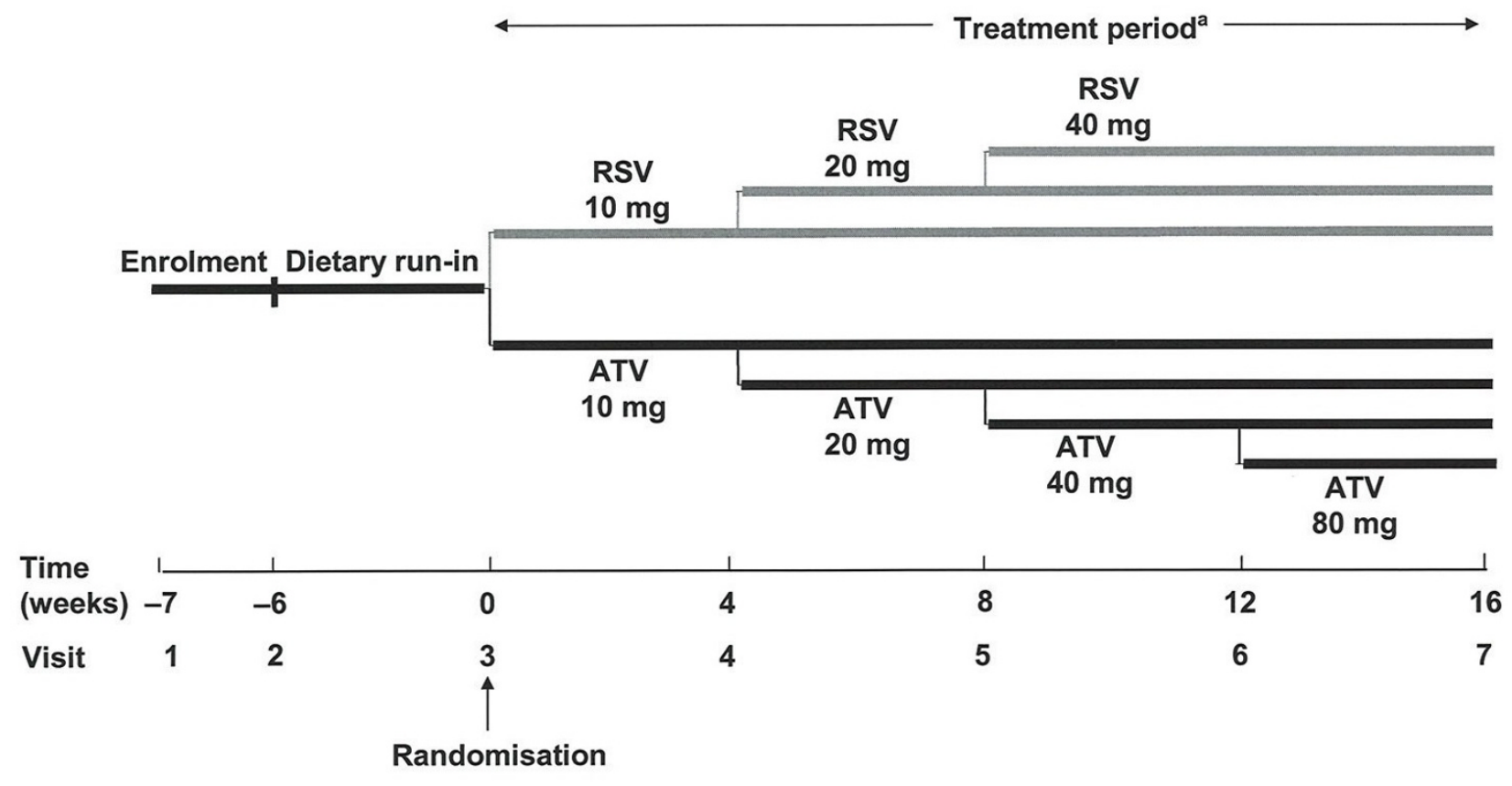

Figure I

Study design. aln patients who had not reached the European goal of LDL-C $<3.0 \mathrm{mmol} / \mathrm{L}$ after 4 weeks, the statin dose was doubled at each visit, up to a maximum of RSV $40 \mathrm{mg}$ and ATV $80 \mathrm{mg}$ RSV: Rosuvastatin, ATV: Atorvastatin, LDL-C: Lowdensity lipoprotein cholesterol

statin dose (rosuvastatin $20 \mathrm{mg}$ or atorvastatin $20 \mathrm{mg}$ ). Further dose titrations (to rosuvastatin $40 \mathrm{mg}$, or atorvastatin $40 \mathrm{mg}$ or $80 \mathrm{mg}$ ) were performed at 8 weeks and 12 weeks for patients who were still not at their LDL-C goal. Patients whose LDL-C level was below the goal at 4 weeks continued on the initial dose of study medication; if their LDL-C level exceeded the goal at subsequent visits, study medication was up-titrated.

Concomitant treatment with erythromycin, azole antimycotic agents, vitamin $\mathrm{K}$ antagonists, immunosuppressive agents, glitazones or systemic steroids was not permitted during the study. If insulin treatment became necessary, or if the patient took lipid-lowering medication (other than study medication), the patient was discontinued from the trial.

\section{Assessments}

Efficacy

The primary endpoint was the percentage change in LDL$\mathrm{C}$ from baseline (randomisation) to 16 weeks. Secondary endpoints included: percentage change in LDL-C from baseline to 4 weeks; percentage of patients achieving the
1998 European LDL-C goal at 4 and 16 weeks; percentage change in total cholesterol (TC), TG, high-density lipoprotein cholesterol (HDL-C), the LDL-C/HDL-C ratio, the non-HDL-C/HDL-C ratio, the TC/HDL-C ratio, apolipoprotein (apo) B, apo A-I and the apo B/apo A-I ratio from baseline to 4 and 16 weeks; and the number of titration steps at 16 weeks. A tertiary endpoint was the difference in overnight urinary albumin excretion (UAE) from baseline to 16 weeks.

All patients were instructed to fast for 8 hours prior to giving blood samples. LDL-C levels were measured using a direct method with enzymatic colorimetry (Genzyme Diagnostics, Genzyme Corporation, Cambridge, MA, USA). All analyses were conducted at a central laboratory.

Safety

Adverse events spontaneously reported by the patients, elicited in response to an open question or revealed by observation, were recorded at each visit. Laboratory safety variables included: blood haemoglobin, platelet count, leucocyte count, serum aspartate aminotransferase (ASAT), serum alanine aminotransferase (ALAT), serum 
alkaline phosphatase, serum bilirubin, $\mathrm{CK}$, serum creatinine and glycated haemoglobin $\left(\mathrm{HbA}_{1 \mathrm{c}}\right)$. All analyses were performed at a central laboratory.

\section{Statistical methods}

In order to have a $90 \%$ chance of detecting a difference between the two treatment arms of $6 \%$ in the primary endpoint (percentage change in LDL-C from baseline to 16 weeks), 212 patients per arm were required to complete the study. The primary efficacy endpoint was determined using analysis of covariance with change in LDL-C as response variable, treatment and centre as factors, and baseline LDL-C as covariate. Percentage change in other lipid variables from baseline to 4 weeks and 16 weeks, and percentage change in UAE, were analysed in the same way as the primary endpoint. The proportion of patients reaching LDL-C goal was analysed using a Mantel-Haenszel test stratified by centre. All tests were two-sided with a significance level of 5\%. In addition, 95\% confidence intervals were calculated for the treatment differences in all efficacy variables except the percentage of patients reaching LDL-C goal.

All efficacy variables were analysed in the intention-totreat population (observed data). Analysis of the primary endpoint was also carried out using the last observation carried forward approach. All enrolled patients were evaluated for safety.

\section{Results}

\section{Demographics}

A total of 469 patients were randomised, and efficacy data were obtained from 465 patients, 232 in the rosuvastatin group and 233 in the atorvastatin group (figure 2). The two groups were well matched at baseline, and demographic details are shown in table 1. Previous statin treatment was received by 31 patients (13\%) in the rosuvastatin group and 39 patients (17\%) in the atorvastatin group. Eleven patients in the rosuvastatin group and 12 in the atorvastatin group discontinued during the randomised treatment period (figure 2).

\section{Efficacy}

At the end of the titration-to-goal period, rosuvastatin was significantly more effective than atorvastatin on the primary efficacy measure, reducing LDL-C by $52 \%$ compared with $46 \%$ in the atorvastatin group $(\mathrm{p}<0.0001)$ (table 2$)$. In line with its greater efficacy for LDL-C reduction, significantly more rosuvastatin-treated patients reached the 1998 European LDL-C goal after 16 weeks than atorvastatin-treated patients ( $94 \%$ vs $88 \%, \mathrm{p}<0.05)$. Furthermore, more patients achieved the goal on the starting dose of rosuvastatin than atorvastatin (75\% vs $54 \%$ ) (figure 3 ). The greater ability of rosuvastatin to lower LDL-C was also reflected by the number of dose titrations required by each treatment group; a total of 75 titration steps were required by rosuvastatin-treated patients compared with 155 titrations in the atorvastatin group.

During the 4-week fixed-dose period, significantly more patients on rosuvastatin $10 \mathrm{mg}$ had reached the 1998 European LDL-C goal compared with patients on atorvastatin $10 \mathrm{mg}$ (figure 4). When data from the fixed-dose period were re-analysed to the more stringent 2003 European LDL-C goal of $<2.5 \mathrm{mmol} / \mathrm{L}, 65 \%$ of patients receiving rosuvastatin $10 \mathrm{mg}$ achieved goal compared with $33 \%$ of patients receiving atorvastatin $10 \mathrm{mg}(\mathrm{p}<0.001$; figure $4)$.

Rosuvastatin also reduced TC, non-HDL-C, LDL-C/HDL$\mathrm{C}$ ratio, non-HDL-C/HDL-C ratio, and TC/HDL-C ratio significantly $(\mathrm{p}<0.0001)$ more than atorvastatin after 4 weeks of treatment (table 3). Both treatments increased HDL-C and decreased TG from baseline to 4 weeks, but there were no statistically significant differences between the groups (table 3 ). In addition, rosuvastatin significantly reduced levels of apo B and the apo B/apo A-I ratio, and increased apo A-I levels compared with atorvastatin $(\mathrm{p} \leq 0.05)$ (table 3). Similar significant effects on TC, nonHDL-C, apolipoproteins and lipid ratios were observed at 16 weeks (table 2 ).

There was no statistically significant difference in UAE rate from baseline to study end, or between the treatment groups, including those patients with baseline microalbuminuria (UAE $>20 \mu \mathrm{g} / \mathrm{min}$ ).

\section{Safety}

Both treatments were well tolerated, with overall incidences of adverse events being similar between the treatment groups $(51 \%$ with rosuvastatin, $53 \%$ with atorvastatin). A total of 10 patients experienced serious adverse events (two in the rosuvastatin group, eight in the atorvastatin group), none of which were considered by the investigator to be related to study treatment. Ten patients discontinued because of adverse events, three in the rosuvastatin group and seven in the atorvastatin group. There were no cases of myopathy. Myalgia was reported by $3.4 \%$ of the patients in the study; none of the cases were associated with a clinically important elevation in CK $(>5 \times$ ULN). Indeed, there were no clinically important elevations in CK in either group throughout the study and changes in CK were not related to dose of study medication or duration of treatment. The most frequent adverse events overall were nasopharyngitis, myalgia, and inadequately controlled diabetes mellitus (table 4). There were no clinically relevant changes in ALAT or ASAT $(>3 \times$ ULN). 


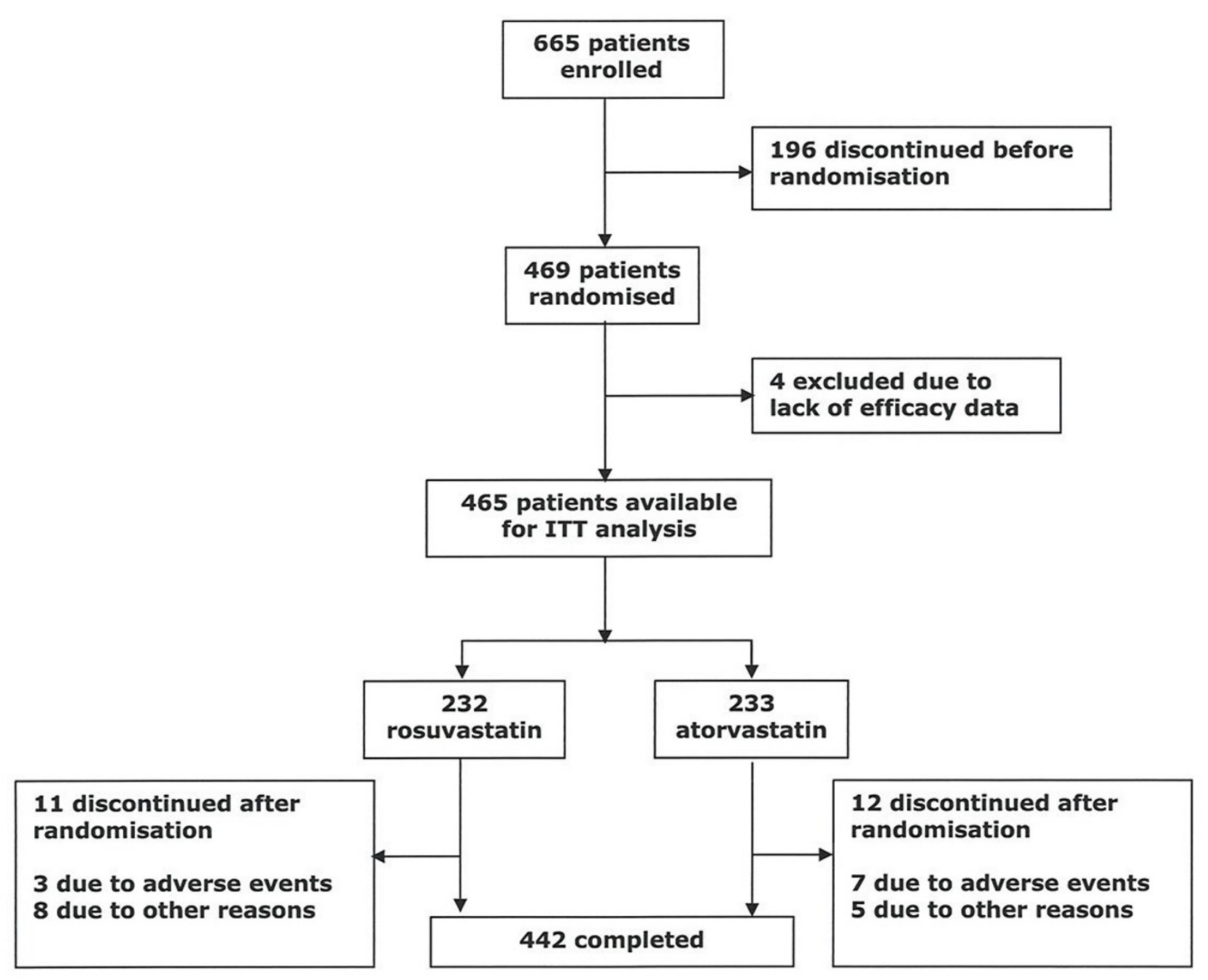

Figure 2

Study populations

Table I: Patient demographics of ITT population

\begin{tabular}{lcc}
\hline & Rosuvastatin (n = 232) & Atorvastatin (n = 233) \\
\hline Gender, male/female (\%) & $128 / 104(55.2 / 44.8)$ & $136 / 97(58.4 / 41.6)$ \\
Race, white (\%) & $229(98.7)$ & $229(98.3)$ \\
Mean age, years (SD) & $63.5(8.8)$ & $65.0(8.6)$ \\
Mean weight, $\mathrm{kg}$ (SD) & $84.8(14.3)$ & $82.5(13.5)$ \\
Mean BMI, $\mathrm{kg} / \mathrm{m}^{2}$ (SD) & $29.0(3.6)$ & $28.4(3.6)$ \\
Mean baseline LDL-C, mmol/L (SD) & $4.6(0.85)$ & $4.6(0.82)^{\mathrm{a}}$ \\
Mean baseline HDL-C, mmol/L (SD) & $1.2(0.27)$ & $1.2(0.27)^{\mathrm{a}}$ \\
Mean baseline TG, mmol/L (SD) & $2.0(1.0)$ & $2.0(0.93)^{\mathrm{a}}$ \\
\hline
\end{tabular}

ITT: Intention to treat, SD: Standard deviation, BMI: Body mass index, LDL-C: Low-density lipoprotein cholesterol, HDL-C: High-density lipoprotein cholesterol, TG: Triglycerides $a_{n}=232$ 
Table 2: Percentage change from baseline in lipid variables at 16 weeks (ITT population). Doses were titrated from week 4 to week 16 in patients who had not reached the 1998 European LDL-C goal $(<3.0 \mathrm{mmol} / \mathrm{L})$

\begin{tabular}{|c|c|c|c|c|}
\hline \multirow[t]{2}{*}{ Variable } & \multicolumn{2}{|c|}{$\begin{array}{l}\text { Least-squares mean percentage change from } \\
\text { baseline to } 16 \text { weeks }\end{array}$} & \multirow[t]{2}{*}{ Difference $(95 \% \mathrm{Cl})$} & \multirow[t]{2}{*}{ p-value } \\
\hline & $\begin{array}{l}\text { Rosuvastatin } 10-40 \mathrm{mg} \\
(\mathrm{n}=221)\end{array}$ & $\begin{array}{l}\text { Atorvastatin } 10-80 \mathrm{mg} \\
\qquad(\mathrm{n}=220)\end{array}$ & & \\
\hline LDL-C & -52.3 & -45.5 & $-6.7(-8.8,-4.7)$ & $<0.0001$ \\
\hline TC & -35.4 & -31.3 & $-4.1(-5.8,-2.4)$ & $<0.0001$ \\
\hline HDL-C & 5.3 & 4.0 & $1.3(-1.3,3.8)$ & NS \\
\hline TG & -21.2 & -21.1 & $-0.1(-5.6,5.3)$ & NS \\
\hline Non-HDL-C & -45.0 & -39.6 & $-5.5(-7.4,-3.5)$ & $<0.0001$ \\
\hline LDL-C/HDL-C ratio & -54.1 & -47.0 & $-7.1(-9.3,-4.9)$ & $<0.0001$ \\
\hline Non-HDL-C/HDL-C ratio & -47.1 & -40.9 & $-6.2(-8.6,-3.9)$ & $<0.0001$ \\
\hline TC/HDL-C ratio & -38.0 & -33.1 & $-5.0(-6.9,-3.0)$ & $<0.0001$ \\
\hline Apo B & -45.2 & -40.1 & $-5.1(-7.2,-3.1)$ & $<0.0001$ \\
\hline Apo A-I & 2.6 & -0.2 & $2.8(1.0,4.6)$ & 0.0024 \\
\hline Apo B/apo A-I ratio & -46.3 & -39.6 & $-6.7(-8.9,-4.6)$ & $<0.0001$ \\
\hline
\end{tabular}

ITT: Intention to treat, CI: Confidence interval, LDL-C: Low-density lipoprotein cholesterol, TC: Total cholesterol, HDL-C: High-density lipoprotein cholesterol, TG: Triglycerides, Apo: Apolipoprotein, NS: Not statistically significant

\section{Discussion}

Rosuvastatin provided significantly greater LDL-C reductions than atorvastatin, both at the initial dose of $10 \mathrm{mg}$ and also when titrated over the dose range of $10-40 \mathrm{mg}$ for rosuvastatin and 10-80 mg for atorvastatin. In addition, a significantly higher percentage of patients treated with rosuvastatin achieved the 1998 European LDL-C goal ( $<3.0 \mathrm{mmol} / \mathrm{L}$ ), both with the starting dose of $10 \mathrm{mg}$ and after the period of dose titration. These results are consistent with the findings of studies in patients with hypercholesterolaemia that compared rosuvastatin with atorvastatin over 6 weeks [25], 8 weeks [31], 12 weeks $[27,28]$, and 52-week dose titration [28].

Patients with type 2 diabetes commonly have a highly atherogenic lipid profile including elevated LDL-C, increased TG and low HDL-C, which is associated with a high risk of developing cardiovascular disease [32,33]. Statins are recognized as first-line therapy for cholesterol lowering, and their benefits have been shown to extend to patients with diabetes [18-22]. The present study was designed to reflect the treatment of diabetic dyslipidaemia in the clinical setting, in that statin treatment of patients was titrated upwards from the recommended starting dose to that required to achieve the 1998 European target of LDL-C $<3.0 \mathrm{mmol} / \mathrm{L}$. The population of the present study was compared with patients with type 2 diabetes in the Swedish National Diabetes Registry and was found to be consistent in terms of baseline characteristics such as age, $\mathrm{HbA}_{1 \mathrm{c}}$, body mass index, percentage of smokers, blood pressure, and antidiabetic medication [34].
New European guidelines published in 2003 recommend a more stringent target (LDL-C $<2.5 \mathrm{mmol} / \mathrm{L}$ ) [9] than that used when the present study was planned. Further analysis of the 4-week (fixed-dose) LDL-C data indicated that rosuvastatin $10 \mathrm{mg}$ treated significantly more patients to the new 2003 European goal of $<2.5 \mathrm{mmol} / \mathrm{L}$ than atorvastatin $10 \mathrm{mg}$. As expected, the absolute percentages of patients achieving the more stringent 2003 goal were lower than the absolute percentages achieving the 1998 goal at 4 weeks, but the greater efficacy of rosuvastatin 10 mg compared with atorvastatin $10 \mathrm{mg}$ remained the same. As more clinical trial evidence becomes available regarding the positive effects of intensive lipid lowering among patients with diabetes, it is likely that even more stringent LDL-C goals will be recommended. Indeed, National Cholesterol Education Program Adult Treatment Panel III recommendations were recently reviewed and a target of LDL-C $<70 \mathrm{mg} / \mathrm{dL}(1.8 \mathrm{mmol} / \mathrm{L})$ was suggested as a therapeutic option for individuals considered to be at very high risk including those with both type 2 diabetes and established cardiovascular disease [35].

The availability of an agent that enables a large number of patients to achieve LDL-C goal at the starting dose is important given that many patients receiving lipid-lowering therapy fail to existing attain lipid targets due to a lack of dose titration and the use of less effective agents [36,37]. A recent observational study, designed to reflect dyslipidaemia treatment in the clinical setting, evaluated the number of hyperlipidaemic patients with coronary heart disease or diabetes who achieved LDL-C goal with their initial statin dose and whether patients were dose 


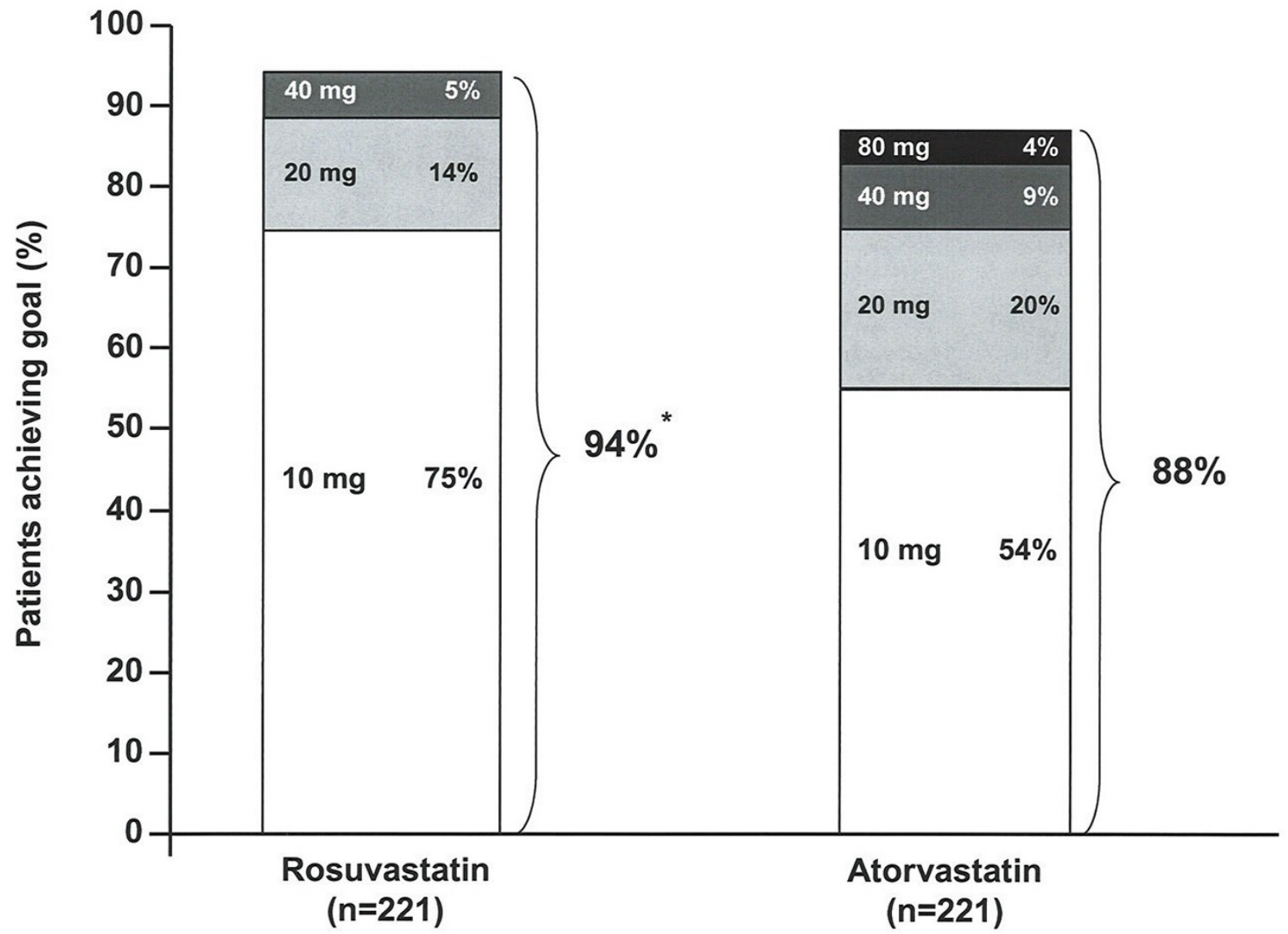

Figure 3

Cumulative percentage of patients to 1998 European LDL-C goal of $<3.0 \mathrm{mmol} / \mathrm{L}$ [7] by dose at I6 weeks. *p < 0.05 rosuvastatin 10-40 mg vs atorvastatin 10-80 mg RSV: Rosuvastatin, ATV: Atorvastatin, LDL-C: Low-density lipoprotein cholesterol

titrated [38]. Less than half (48\%) achieved LDL-C $<2.6$ $\mathrm{mmol} / \mathrm{L}$ with their initial dose and, of those who did not achieve goal, only $45 \%$ had their dose titrated. Dose titration increases costs and the need for follow-up, which, while necessary, can be time-consuming and inconvenient. The ability of rosuvastatin to enable greater proportions of patients to achieve LDL-C goal, with reduced requirement for dose titration is highly advantageous.

The benefits of reaching treatment goals have been demonstrated in the Steno-2 study [39], in which patients with type 2 diabetes were randomised to receive conventional treatment or intensive multifactorial intervention to strict treatment goals (including TC $<4.5 \mathrm{mmol} / \mathrm{L}$ ). LDL-C levels were reduced by $47 \%$ in those receiving intensive therapy, and the risk of both cardiovascular and microvascular events was reduced by approximately $50 \%$ compared with conventional treatment [39].

Rosuvastatin was also more effective than atorvastatin in reducing a range of other lipid variables, including $\mathrm{TC}$, non-HDL-C, LDL-C/HDL-C ratio, non-HDL-C/HDL-C ratio, and TC/HDL-C ratio. Reductions in TC and/or TC/ HDL-C are particularly relevant given that the Systemic Coronary Risk Evaluation (SCORE) system advocated in the new European guidelines uses these variables to estimate total risk [9].

In the present study, both treatments produced similar increases in HDL-C, which were lower than those 

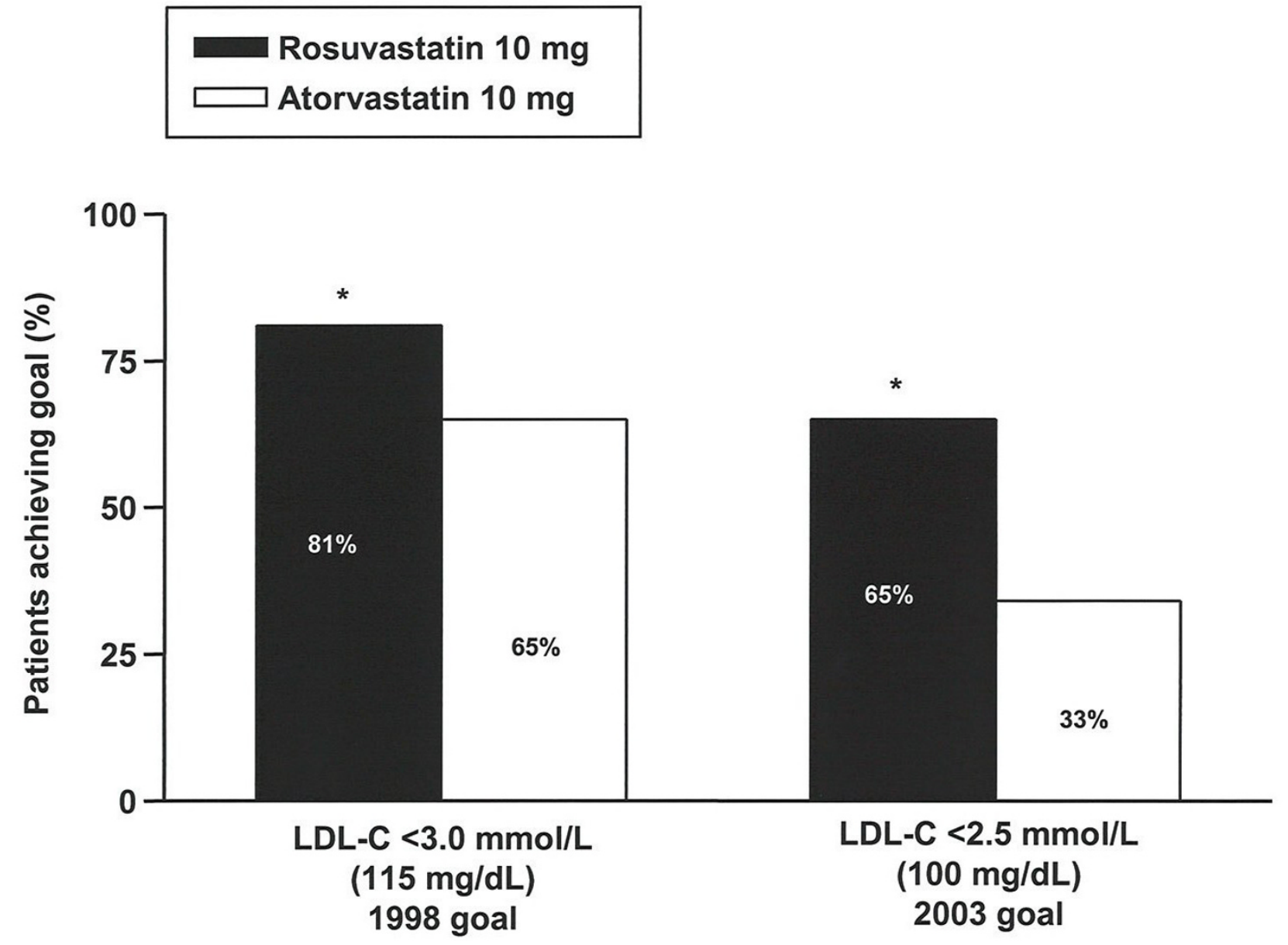

Figure 4

Percentage of patients to 1998 and 2003 European LDL-C goals [7,9] at 4 weeks. *p $<0.00$ I vs atorvastatin LDLC: Low-density lipoprotein cholesterol

observed previously. In the Measuring Effective Reductions in Cholesterol Using Rosuvastatin therapY (MERCURY I) study involving 3,161 patients with hypercholesterolaemia, 8 weeks' treatment with rosuvastatin $10 \mathrm{mg}$ increased HDL-C by $9.2 \%$ and this was significantly greater than atorvastatin $10 \mathrm{mg}(6.8 \%)$ and atorvastatin $20 \mathrm{mg}(5.7 \%)(\mathrm{p}<0.01)$ [31]. In the current study, average baseline HDL-C values were higher than would be expected in the diabetic population, which could partly explain the relatively small increases in HDLC compared with other studies $[31,40]$.

In the present study, the main apolipoprotein in HDL-C, apo A-I, was significantly increased by rosuvastatin compared with atorvastatin $(\mathrm{p}<0.05)$. In addition, significant reductions were also observed in apo B and apo B/apo AI ( $p<0.0001)$. Changes in apolipoprotein levels may have important implications in the reduction of cardiovascular risk, since results from the Apolipoprotein-related Mortality Risk (AMORIS) study indicate that apo B, apo A-I and apo B/apo A-I are powerful predictors of cardiac events [41]. Taken together with the other changes to lipid variables, the findings of the present study indicate that a less atherogenic lipid profile was achieved with rosuvastatin.

Treatment of diabetic dyslipidaemia may also reduce the incidence of microvascular disease including nephropathy [33]. Statins have been shown to have beneficial effects in diabetic nephropathy by reducing the rate of UAE $[42,43]$. In the present study, statin treatment did not 
Table 3: Percentage change from baseline in lipid variables at 4 weeks (ITT population)

\begin{tabular}{|c|c|c|c|c|}
\hline \multirow[t]{2}{*}{ Variable } & \multicolumn{2}{|c|}{$\begin{array}{c}\text { Least-squares mean percentage change from } \\
\text { baseline to } 4 \text { weeks }\end{array}$} & \multirow[t]{2}{*}{ Difference $(95 \% \mathrm{CI})$} & \multirow[t]{2}{*}{ p-value } \\
\hline & $\begin{array}{c}\text { Rosuvastatin } 10 \mathrm{mg}(\mathrm{n}= \\
232)\end{array}$ & $\begin{array}{l}\text { Atorvastatin } 10 \mathrm{mg}(\mathrm{n}= \\
23 \mathrm{I})\end{array}$ & & \\
\hline LDL-C & -47.6 & $-38.5^{a}$ & $-9.1(-11.4,-6.7)$ & $<0.0001$ \\
\hline TC & -33.6 & -27.9 & $-5.7(-7.4,-4.0)$ & $<0.0001$ \\
\hline HDL-C & 4.4 & 2.6 & I.8 $(-0.5,4.0)$ & NS \\
\hline TG & -19.2 & -15.5 & $-3.7(-9.5,2.2)$ & NS \\
\hline Non-HDL-C & -42.6 & -35.0 & $-7.6(-9.6,-5.7)$ & $<0.0001$ \\
\hline LDL-C/HDL-C ratio & -49.3 & -39.5 & $-9.8(-12.2,-7.4)$ & $<0.0001$ \\
\hline Non-HDL-C/HDL-C ratio & -44.4 & -35.9 & $-8.5(-10.8,-6.2)$ & $<0.0001$ \\
\hline TC/HDL-C ratio & -35.8 & -29.0 & $-6.7(-8.7,-4.8)$ & $<0.0001$ \\
\hline Apo B & -42.9 & -35.3 & $-7.6(-9.7,-5.6)$ & $<0.0001$ \\
\hline Apo A-I & 2.6 & 0.8 & $1.8(0,3.5)$ & 0.05 \\
\hline Apo B/apo A-I ratio & -43.9 & -35.4 & $-8.5(-10.6,-6.4)$ & $<0.0001$ \\
\hline
\end{tabular}

ITT: Intention to treat, Cl: Confidence interval, LDL-C: Low-density lipoprotein cholesterol, TC: Total cholesterol, HDL-C: High-density lipoprotein cholesterol, TG: Triglycerides, Apo: Apolipoprotein, NS: Not statistically significant $a_{n}=232$

Table 4: Adverse events occurring in $\geq 3 \%$ of patients in any treatment group

\begin{tabular}{lcc}
\hline & Number (\%) of patients with adverse event \\
\hline Adverse event & Rosuvastatin (n= 233) & Atorvastatin (n= 236) \\
\hline Nasopharyngitis & $23(9.9)$ & $19(8.1)$ \\
Myalgia & $13(5.6)$ & $7(3.0)$ \\
Inadequately controlled diabetes mellitus & $14(6.0)$ & $11(4.6)$ \\
Constipation & $9(3.9)$ & $6(2.5)$ \\
Headache & $6(2.6)$ & $7(3.0)$ \\
Urinary tract infection & $9(3.9)$ & $2(0.9)$ \\
Arthralgia & $1(0.4)$ & $9(3.8)$ \\
\hline
\end{tabular}

significantly alter the rate of UAE; however, this may reflect the fact that the treatment period was relatively short. Previously, a reduced UAE rate with statin therapy has been observed after at least 6 months' treatment $[42,43]$.

Both treatments were similarly well tolerated, with no unexpected safety concerns, and tolerability was similar to that previously observed in non-diabetic patient populations $[40,44]$.

In conclusion, rosuvastatin was significantly more effective at reducing LDL-C and achieving European LDL-C goals both during the fixed-dose period and following dose titration than atorvastatin in patients with type 2 diabetes.

\section{Competing interests}

This study was supported by AstraZeneca, Södertälje, Sweden, which provided study expenses and covered the article processing charge. Annica Siewert-Delle is an employee of AstraZeneca.

\section{Authors' contributions}

Christian Berne and Annica Siewert-Delle participated in the design and coordination of the study and prepared the manuscript. Both authors read and approved the final manuscript.

\section{Acknowledgements}

We gratefully acknowledge the investigators, their co-investigators and study co-ordinators, and the patients who participated in this trial.

In addition to the authors of this publication, the following investigators participated in this trial: R Ekesbo, Dalby; L Fröberg, Höganäs; N Henning- 
sen, Malmö; G Ilestam, Malmö; A Fahlbom, Malmö; J Nielsen, Skivarp; S Nordström, Knislinge; N Nörgaard, Höganäs; G Vatnaland, Ängelholm; AC Knutsson, Ängelholm; J Wiuff, Oskarshamn; C Sjödin, Växjö; T Svensson, Växjö; G Tygesen, Lagan; O Benéus, Partille; L Benéus, Partille; L Lingetun, Falkenberg; I Wallin, Mölndal; J Alvång, Trollhättan; E Angesjö, Borås; P HelIke, Göteborg; L Nord, Stenungsund; C Andersson, Stenungsund; U Thorslund, Göteborg; M Öhberg, Skene; P E:son Jennersjö, Linköping; O Borgholst, Kungsör; B Cöster, Kristinehamn; G Holmberg, Karlstad; W Meyer, Köping; B Finger, Köping; R Baylis, Köping; E Sundequist-Stockhaus, Karlstad; P Sundin, Örebro; K Vetterskog, Västerås; J-E Andersson, Tyresö; G Widerström, Tyresö; A Bröijersen, Stockholm; B Thorsson, Stockholm; B Eriksson, Gustavsberg; H Noppa, Spånga; A Häggmark, Skärholmen; L Held, Skärholmen; H Salminen, Bagarmossen AB; P Nordström, Bagarmossen AB; R Zlatewa-Cuenca, Stockholm; L Hjelmaeus, Stockholm; E Hammarström, Stockholm; K Brismar, Stockholm; I Bäckström, Märsta; S Hellerstedt, Kungsbacka; L Håkansson, Norrtälje; A Lindh, Åkersberga; RM Brinkeborn, Uppsala; T Lundmark, Kilafors; U Sundström, Kilafors; R Malmström, Sandviken; E Tönnesen, Uppsala; E Edén, Uppsala; K Åresund, Gävle; O Berglund, Umeå; K Henriksson, Krokom; L Lönneborg, Sundsbruk; M Mullaart, Sundsbruk; P Malm, Östersund; G Strömberg, Trehörningsjö; T Lindén, Västra Frölunda.

\section{References}

I. Wild S, Roglic G, Green A, Sicree R, King H: Global prevalence of diabetes: estimates for the year 2000 and projections for 2030. Diabetes Care 2004, 27:1047-1053.

2. Laakso M: Cardiovascular disease in type 2 diabetes: challenge for treatment and prevention. J Intern Med 200I, 249:225-235.

3. Herlitz J, Malmberg K, Karlson BW, Ryden L, Hjalmarson A: Mortality and morbidity during a five-year follow-up of diabetics with myocardial infarction. Acta Med Scand 1988, 224:3I-38.

4. Norhammar A, Malmberg K, Ryden L, Tornvall P, Stenestrand U, Wallentin L: Under utilisation of evidence-based treatment partially explains for the unfavourable prognosis in diabetic patients with acute myocardial infarction. Eur Heart J 2003, 24:838-844.

5. Kleinman JC, Donahue RP, Harris MI, Finucane FF, Madans JH, Brock DB: Mortality among diabetics in a national sample. $\mathrm{Am} J$ Epidemiol I988, I28:389-40 I.

6. Haffner SM: Statin therapy for the treatment of diabetic dyslipidemia. Diabetes Metab Res Rev 2003, 19:280-287.

7. Wood D, De Backer G, Faergeman O, Graham I, Mancia G, Pyörälä $\mathrm{K}$ : Prevention of coronary heart disease in clinical practice. Recommendations of the second joint task force of European and other societies on coronary prevention. Eur Heart J 1998, 19:1434-1503.

8. European Diabetes Policy Group: A desktop guide to type 2 diabetes mellitus. Diabet Med 1999, 16:716-730.

9. De Backer G, Ambrosioni E, Borch-Johnsen K, Brotons C, Cifkova R, Dallongeville J, Ebrahim S, Faergeman O, Graham I, Mancia G, Cats VM, Orth-Gomer K, Perk J, Pyörälä K, Rodicio JL, Sans S, Sansoy V, Sechtem U, Silber S, Thomsen T, Wood D, European Society of Cardiology Committee for Practice Guidelines: European guidelines on cardiovascular disease prevention in clinical practice: third joint task force of European and other societies on cardiovascular disease prevention in clinical practice. Eur J Cardiovasc Prev Rehabil 2003, I O(Suppl I):SI-S78.

10. American Diabetes Association: Management of dyslipidemia with diabetes. Diabetes Care 2002, 25(SuppI I):S74-S77.

1I. Expert Panel on Detection, Evaluation and Treatment of High Blood Cholesterol in Adults: Executive summary of the third report of the National Cholesterol Education Program (NCEP) expert panel on detection, evaluation and treatment of high blood cholesterol in adults (Adult Treatment Panel III). JAMA 200I, 285:2486-2497.

12. Scandinavian Simvastatin Survival Study (4S): Randomised trial of cholesterol lowering in $\mathbf{4 4 4 4}$ patients with coronary heart disease: the Scandinavian Simvastatin Survival Study (4S). Lancet 1994, 344: I383-1389.

13. Shepherd J, Cobbe SM, Ford I, Isles CG, Lorimer AR, MacFarlane PW, McKillop JH, Packard C]: Prevention of coronary heart disease with pravastatin in men with hypercholesterolemia. West of Scotland Coronary Prevention Study Group. N Engl J Med 1995, 333:130I-1307.

14. Sacks FM, Pfeffer MA, Moye LA, Rouleau JL, Rutherford JD, Cole TG, Brown L, Warnica JW, Arnold JM, Wun CC, Davis BR, Braunwald E: The effect of pravastatin on coronary events after myocardial infarction in patients with average cholesterol levels. $N$ Engl J Med 1996, 335: 1001-1009.

15. The Long-term Intervention with Pravastatin in Ischaemic Disease (LIPID) Study Group: Prevention of cardiovascular events and death with pravastatin in patients with coronary heart disease and a broad range of initial cholesterol levels. $N$ Engl Med 1998, 339: 1349-1357.

16. Downs JR, Clearfield M, Weis S, Whitney E, Shapiro DR, Beere PA, Langendorfer A, Stein EA, Kruyer W, Gotto AM Jr: Primary prevention of acute coronary events with lovastatin in men and women with average cholesterol levels. Results of AFCAPS/ TexCAPS. JAMA 1998, 279:1615-1622.

17. Sever PS, Dahlof B, Poulter NR, Wedel H, Beevers G, Caulfield M, Collins R, Kjeldsen SE, Kristinsson A, Mclnnes GT, Mehlsen J, Nieminen M, O'Brien E, Ostergren J, ASCOT investigators: Prevention of coronary and stroke events with atorvastatin in hypertensive patients who have average or lower-than-average cholesterol concentrations, in the Anglo-Scandinavian Cardiac Outcomes Trial-Lipid Lowering Arm (ASCOT-LLA): a multicentre randomised controlled trial. Lancet 2003, 36 I: II 149-1158.

18. Pyörälä K, Pedersen TR, Kjekshus J, Faergeman O, Olsson AG, Thorgeirsson G: Cholesterol lowering with simvastatin improves prognosis of diabetic patients with coronary heart disease. A subgroup analysis of the Scandinavian Simvastatin Survival Study (4S). Diabetes Care 1997, 20:6 |4-620.

19. Goldberg RB, Mellies MJ, Sacks FM, Moye LA, Howard BV, Howard W], Davis BR, Cole TG, Pfeffer MA, Braunwald E: Cardiovascular events and their reduction with pravastatin in diabetic and glucose-intolerant myocardial infarction survivors with average cholesterol levels: subgroup analyses in the Cholesterol And Recurrent Events (CARE) trial. Circulation 1998, 98:2513-2519.

20. Keech A, Colquhoun D, Best J, Kirby A, Simes RJ, Hunt D, Hague W, Beller E, Arulchelvam M, Baker J, Tonkin A, LIPID Study Group: Secondary prevention of cardiovascular events with long-term pravastatin in patients with diabetes or impaired fasting glucose: results from the LIPID trial. Diabetes Care 2003, 26:27|3-272I.

21. Collins R, Armitage J, Parish S, Sleigh P, Peto R, Heart Protection Study Collaborative Group: MRC/BHF Heart Protection Study of cholesterol-lowering with simvastatin in 5963 people with diabetes: a randomised placebo-controlled trial. Lancet 2003, 36 I:2005-2016

22. Colhoun HM, Betteridge DJ, Durrington PN, Hitman GA, Neil HA Livingstone SJ, Thomason MJ, Mackness MI, Charlton-Menys V, Fuller $\mathrm{JH}$, CARDS investigators: Primary prevention of cardiovascular disease with atorvastatin in type 2 diabetes in the Collaborative Atorvastatin Diabetes Study (CARDS): multicentre randomized placebo-controlled trial. Lancet 2004, 364:685-696.

23. del Canizo-Gomez FJ, Moreira-Andres MN: Cardiovascular risk factors in patients with type 2 diabetes. Do we follow the guidelines? Diabetes Res Clin Pract 2004, 65: 125-133.

24. Betteridge JD, Leiter LA, AUDIT Investigators: The AUDIT Study: regional variations in physicians attitudes to diabetic dyslipidaemia. Diabetologia 2004, 47(Suppl I):A73

25. Jones PH, Davidson MH, Stein EA, Bays HE, McKenney JM, Miller E, Cain VA, Blasetto JW, STELLAR Study Group: Comparison of the efficacy and safety of rosuvastatin versus atorvastatin, simvastatin and pravastatin across doses (STELLAR) trial. Am J Cardiol 2003, 92:152-160.

26. Kritharides L: Reducing low-density lipoprotein cholesterol treating to target and meeting new European goals. Eur Heart 2004, 6(Suppl A):AI-A7.

27. Davidson M, Ma P, Stein EA, Gotto AM Jr, Raza A, Chitra R, Hutchinson $\mathrm{H}$ : Comparison of effects on low-density lipoprotein cholesterol and high-density lipoprotein cholesterol with rosuvastatin versus atorvastatin in patients with type Ila or Ilb hypercholesterolemia. Am / Cardiol 2002, 89:268-275. 
28. Olsson AG, Istad H, Luurila O, Ose L, Stender S, Tuomilehto J, Wiklund $\mathrm{O}$, Southworth $\mathrm{H}$, Pears J, Wilpshaar JW, Rosuvastatin Investigators Group: Effects of rosuvastatin and atorvastatin compared over 52 weeks of treatment in patients with hypercholesterolemia. Am Heart J 2002, I 44: 1044-I05I.

29. Strandberg TE, Feely J, Sigurdsson EL: Twelve-week, multicenter, randomized, open-label comparison of the effects of rosuvastatin $10 \mathrm{mg} / \mathrm{d}$ and atorvastatin $10 \mathrm{mg} / \mathrm{d}$ in high-risk adults: A DISCOVERY study. Clin Therapeut 2004, 26: |82 |-|833.

30. Schuster H, Fox JC: Investigating cardiovascular risk reduction - the rosuvastatin GALAXY programme. Expert Opin Pharmacother 2004, 5: I I87-I200.

31. Schuster H, Barter PJ, Stender S, Cheung RC, Bonnet J, Morrell JM, Watkins C, Kallend D, Raza A, Effective Reductions in Cholesterol Using Rosuvastatin Therapy I study group: Effects of switching statins on achievement of lipid goals: Measuring Effective Reductions in Cholesterol Using Rosuvastatin Therapy (MERCURY I) study. Am Heart J 2004, 147:705-7I3.

32. Turner RC, Millns H, Neil HA, Stratton IM, Manley SE, Matthews DR, Holman RR: Risk factors for coronary artery disease in noninsulin dependent diabetes mellitus: United Kingdom prospective diabetes study (UKPDS:23). BMJ 1998, 316:823-828.

33. Krentz A): Lipoprotein abnormalities and their consequences for patients with type 2 diabetes. Diabetes Obes Metab 2003, 5(Suppl I):SI9-27.

34. Gudbjörnsdottir S, Cederholm J, Nilsson PM, Eliasson B, Steering Committee of the Swedish National Diabetes Register: The National Diabetes Register in Sweden: an implementation of the St. Vincent Declaration for Quality Improvement in Diabetes Care. Diabetes Care 2003, 26:1270-1276.

35. Grundy SM, Cleeman JI, Merz CN, Brewer HB Jr, Clark LT, Hunninghake DB, Pasternak RC, Smith SC Jr, Stone NJ, National Heart, Lung, and Blood Institute; American College of Cardiology Foundation; American Heart Association: Implications of recent clinical trials for the National Cholesterol Education Program Adult Treatment Panel III guidelines. Circulation 2004, I I 0:227-239.

36. Pearson TA, Laurora I, Chu H, Kafonek S: The Lipid Treatment Assessment Project (L-TAP). A multicenter survey to evaluate the percentages of dyslipidemic patients receiving lipidlowering therapy and achieving low-density lipoprotein cholesterol goals. Arch Intern Med 2000, 160:459-467.

37. EUROASPIRE II Study Group: Lifestyle and risk factor management and use of drug therapies in coronary patients from 15 countries: principal results from EUROASPIRE II. Eur Heart J 2001, 22:554-572.

38. Foley KA, Simpson RJ Jr, Crouse JR 3rd, Weiss TW, Markson LE, Alexander CM: Effectiveness of statin titration on low-density lipoprotein cholesterol goal attainment in patients at high risk of atherogenic events. Am J Cardiol 2003, 92:79-8I.

39. Gaede P, Vedel P, Larsen N, Jensen GV, Parving HH, Pedersen O: Multifactorial intervention and cardiovascular disease in patients with type 2 diabetes. N Engl J Med 2003, 348:383-393.

40. Olsson AG, McTaggart F, Raza A: Rosuvastatin: a highly effective new HMG-CoA reductase inhibitor. Cardiovasc Drug Rev 2002, 20:303-328.

4I. Walldius G, Jungner I, Holme I, Aastveit AH, Kolar W, Steiner E: High apolipoprotein B, low apolipoprotein A-I, and improvement in the prediction of fatal myocardial infarction (AMORIS study): a prospective study. Lancet 200I, 358:2026-2033.

42. Tonolo G, Ciccarese M, Brizzi P, Puddu L, Secchi G, Calvia P, Atzeni MM, Melis MG, Maioli M: Reduction of albumin excretion rate in normotensive microalbuminuric type 2 diabetic patients during long-term simvastatin treatment. Diabetes Care 1997, 20:189|-1895

43. Nakamura T, Ushiyama C, Hirokawa K, Osada S, Shimada N, Koide $\mathrm{H}$ : Effect of cerivastatin on urinary albumin excretion and plasma endothelin-I concentrations in type 2 diabetes patients with microalbuminuria and dyslipidemia. $\mathrm{Am} \mathrm{J}$ Nephrol 200I, 21:449-454.

44. Rosenson RS: Rosuvastatin: a new inhibitor of HMG-CoA reductase for the treatment of dyslipidemia. Expert Rev Cardiovasc Ther 2003, I:495-505.
Publish with Biomed Central and every scientist can read your work free of charge

"BioMed Central will be the most significant development for disseminating the results of biomedical research in our lifetime. "

Sir Paul Nurse, Cancer Research UK

Your research papers will be:

- available free of charge to the entire biomedical community

- peer reviewed and published immediately upon acceptance

- cited in PubMed and archived on PubMed Central

- yours - you keep the copyright

Submit your manuscript here:

http://www.biomedcentral.com/info/publishing_adv.asp
BiolMedcentral 